\title{
Ultrastructural Immunocytochemical Localization of $\mu$-Opioid Receptors in Rat Nucleus Accumbens: Extrasynaptic Plasmalemmal Distribution and Association with Leu ${ }^{5}$-Enkephalin
}

\author{
Adena L. Svingos, ${ }^{1}$ Akiyoshi Moriwaki, ${ }^{2}$ Jia Bei Wang, ${ }^{2}$ George R. Uhl, ${ }^{2}$ and Virginia M. Pickel ${ }^{1}$ \\ ${ }^{1}$ Division of Neurobiology, Department of Neurology and Neuroscience, Cornell University Medical College, New York, \\ New York 10021, and Intramural Research Program, National Institute on Drug Abuse, National Institutes of Health, and \\ Departments of Neurology and Neuroscience, The Johns Hopkins University, Baltimore, Maryland 21224
}

$\mu$-Opioid receptors and their endogenous ligands, including $\mathrm{Leu}^{5}$ enkephalin (LE), are distributed abundantly in the nucleus accumbens (NAC), a region implicated in mechanisms of opiate reinforcement. We used immunoperoxidase and/or immunogoldsilver methods to define ultrastructural sites for functions ascribed to $\mu$-opioid receptors and potential sites for activation by LE in the NAC. An antipeptide antibody raised against an 18 amino acid sequence of the cloned $\mu$-opioid receptor (MOR) $C$ terminus showed that MOR-like immunoreactivity (MOR-LI) was localized predominantly to extrasynaptic sites along neuronal plasma membranes. The majority of neuronal profiles containing MOR-LI were dendrites and dendritic spines. The dendritic plasma membranes immunolabeled for MOR were near sites of synaptic input from LE-labeled terminals and other unlabeled terminals forming either inhibitory or excitatory type synapses. Unmyelinated axons and axon terminals were also intensely but less frequently immunore- active for MOR. Observed sites for potential axonal associations with LE included coexistence of MOR and LE within the same terminal, as well as close appositions between differentially labeled axons. Astrocytic processes rarely contained detectable MOR-LI, but also were sometimes observed in apposition to LE-labeled terminals. We conclude that in the rat NAC, MOR is localized prominently to extrasynaptic neuronal and more rarely to glial plasma membranes that are readily accessible to released LE and possibly other opioid peptides and opiate drugs. The close affiliation of MOR with spines receiving excitatory synapses and dendrites receiving inhibitory synapses provides the first direct morphological evidence that MOR selectively modulates postsynaptic responses to cortical and other afferents.

Key words: $\mu$-opioid receptor; reinforcement; striatum; enkephalin; morphine; opiates
The nucleus accumbens (NAC) is thought to be a key site for behaviorally rewarding effects of $\mu$-opioid receptor agonists (Koob and Bloom, 1988; Negus and Dykstra, 1989; Wise, 1989; Koob, 1992). Rats will self-administer morphine-like opiates directly into the NAC (Goeders et al., 1984; West and Wise, 1988). Rates of self-administration are enhanced when selective opioid receptor blockers are coadministered (Koob et al., 1984; Vaccarino et al., 1985). These results are consistent with mediation of opiate reinforcement by opioid receptors in the NAC. Negus et al. (1993) also showed that stimulation or antagonism of $\mu$-opioid receptors produces dose-dependent changes in systemic heroin administration, consistent with effects at this receptor.

Electrophysiology has shown that opiates and opioid peptides can reduce excitability of NAC neurons through actions at $\mu$-opioid receptors (McCarthy et al., 1977; Hakan and Henriksen, 1987). Furthermore, pre- and postsynaptic effects of $\mu$-opioid receptor stimulation (Hori et al., 1992; Capogna et al., 1993; Siggins et al., 1995) provide mechanisms for $\mu$-opioid receptor modulation of synaptic transmission (Yuan et al., 1992). Conceivably, attenuation of synaptic transmission could be attributed to

\footnotetext{
Received Oct. 11, 1995; revised April 18, 1996; accepted April 24, 1996.

This research was supported by an Aaron Diamond Foundation Postdoctoral Fellowship to A.L.S., a National Institute on Drug Abuse Grant DA04600 to V.M.P., and the National Institute on Drug Abuse Intramural Research Group. We thank Terence M. Zeigler for his photographic expertise.

Correspondence should be addressed to Dr. Adena L. Svingos, Department of Neurology and Neuroscience, Cornell University Medical College, 411 East 69th Street, New York, NY 10021.

Copyright (C) 1996 Society for Neuroscience $0270-6474 / 96 / 164162-12 \$ 05.00 / 0$
}

$\mu$-opioid receptor-mediated changes in conductance through G-proteins and/or ion channels found in other neuronal populations (Jiang and North, 1992; Chieng and Christie, 1994).

The behavioral and pharmacological evidence for involvement of the NAC in opiate reward is consistent with anatomical localization of $\mu$-opioid receptors in this region. A heterogenous distribution of $\mu$-opioid receptors in the NAC has been shown using autoradiographic localization of selective radioligands (McLean et al., 1986; Mansour et al., 1987; Tempel and Zukin, 1987). Additionally, NAC neurons express mRNA for $\mu$-opioid receptors as seen by in situ hybridization methods (Chen et al., 1993; Delfs et al., 1994; Zastawny et al., 1994; Mansour et al., 1995a). More recently, light microscopic immunocytochemistry has further confirmed the localization of this receptor in the NAC (Arvidsson et al., 1995; Mansour et al., 1995b). Similar regional compartmentalization is seen using immunocytochemical labeling for $\mathrm{Leu}^{5}$-enkephalin (LE) (Meredith et al., 1993), an endogenous ligand for both $\mu$ - and $\delta$-opioid receptors (Simantov et al., 1977; Hughes et al., 1980).

Despite evidence for functional involvement of $\mu$-opioid receptors in reward mechanisms and the known light microscopic distributions of $\mu$-opioid receptors and LE in the NAC, the ultrastructural sites for receptor-mediated functions have not been established. Thus, to address this question we examined the electron microscopic immunocytochemical labeling of an antipeptide antibody against the cloned $\mu$-opioid receptor (MOR) within the rat NAC. With use of either immunogold-silver or immunoperoxidase methods, we showed MOR-like immunoreactivity 
(MOR-LI) localized mainly along extrasynaptic plasma membranes of dendrites but also in axons and astrocytic processes. Additionally, we examined whether there was a cellular substrate for the postulated functional interactions, including MOR and LE. Using dual-labeling methods, we showed that MOR-labeled dendrites were postsynaptic to LE and other unlabeled terminals forming excitatory and inhibitory synapses. These results establish that in the NAC, activation of MOR mainly at postsynaptic but also presynaptic sites may contribute to the rewarding properties of opiates and endogenous enkephalins.

\section{MATERIALS AND METHODS}

Antisera. A rabbit polyclonal antiserum was raised against an 18 amino acid sequence (amino acids 381-398) of the MOR C terminus. The antiserum was characterized previously using MOR-enriched transfected COS cells and Western immunoblots (Surratt et al., 1994). The specificity of the antibody was tested by (1) labeling of tissue and transfected cells with preimmune serum, (2) omission of secondary antibodies, and (3) preincubation of the primary antibody with the C-terminal peptide or a random peptide of the same length. The results of Surratt et al. (1994) showed no observable labeling when the primary antiserum was eliminated and that preadsorption with the appropriate peptide yielded no labeling of brain tissue or transfected cells. Additionally, adsorption controls at the electron microscopic level showed greatly reduced immunolabeling for MOR in tissue processed for either immunogold-silver or immunoperoxidase. The specificity of the MOR antiserum does not preclude the possibility of cross-reactivity with other C-terminal variants of the receptor (Rossi et al., 1995). It should be noted that the antiserum may not recognize every isoform of $\mu$-opioid receptor in all configurations. Thus, MOR is an abbreviation for the cloned $\mu$-opioid receptor sequence within one subtype of $\mu$-opioid receptor.

For dual-labeling studies, we used a commercially available mouse monoclonal antiserum directed against LE (Sera-Lab, Sussex UK). This antibody primarily recognizes LE and cross-reacts with $\mathrm{Met}^{5}$-enkephalin. Limited cross-reactivity was seen with dynorphin, and none was seen with $\beta$-endorphin (Milner et al., 1989). Adsorption controls showed that LE immunolabeling was eliminated by incubation with the antigenic peptide.

Tissue preparation. The methods for tissue preparation and immunolabeling were based on those described previously by Leranth and Pickel (1989). Seven adult (250-350 gm) male Sprague-Dawley rats (Hilltop Lab Animals, Scottsdale, PA) were anesthetized with sodium pentobarbital $(100 \mathrm{mg} / \mathrm{kg}$, i.p.). They were then perfused through the ascending aorta with $40 \mathrm{ml}$ of heparin $(1000 \mathrm{U} / \mathrm{ml}$ in $0.15 \mathrm{M} \mathrm{NaCl}), 50 \mathrm{ml}$ of acrolein $(3.75 \%)$ (Polyscience, Niles, IL), and $200 \mathrm{ml}$ of paraformaldehyde $(2 \%)$ in $0.1 \mathrm{M}$ phosphate buffer (PB), $\mathrm{pH}$ 7.4. The brains were removed and postfixed for $30 \mathrm{~min}$ in $2 \%$ paraformaldehyde. Sections through the NAC were cut on a vibratome at a thickness of 30-40 $\mu \mathrm{m}$, incubated for $30 \mathrm{~min}$ in a solution of $1 \%$ sodium borohydride in $\mathrm{PB}$ to remove active aldehydes, and rinsed in $\mathrm{PB}$ until bubbles from the tissue dissipated. To enhance antibody penetration, tissue sections were then cryoprotected for $15 \mathrm{~min}$ in a solution of $25 \%$ sucrose and $3.5 \%$ glycerol in $0.05 \mathrm{M} \mathrm{PB}$, frozen rapidly in liquid freon followed by liquid nitrogen, and thawed in PB. Tissue sections were then rinsed in $0.1 \mathrm{M} P B$ followed by $0.1 \mathrm{M}$ Tris-buffered saline (TBS), $\mathrm{pH}$ 7.6. Sections were then incubated for 30 min in $1 \%$ bovine serum albumin (BSA) in TBS to minimize nonspecific labeling and processed for single- or dual-labeling.

Immunocytochemistry. All incubations were carried out at room temperature with agitation and were followed by several successive washes with $\mathrm{PB}$, TBS, and PBS. The tissue sections were incubated for $48 \mathrm{hr}$ at $4^{\circ} \mathrm{C}$ in one of the following primary antibody solutions, all of which contained $0.1 \%$ BSA in TBS: (1) MOR $(1: 15,000)$ for single-labeling with immunoperoxidase; (2) MOR (1:10,000) for single-labeling with immunogold-silver; or (3) MOR (1:10,000) with immunogold-silver and LE (1:100) with immunoperoxidase for dual-labeling studies. For adsorption controls, the primary MOR antibody (both the 1:15,000 and the 1:10,000 dilutions) was incubated in adjacent tissue sections from the NAC with the parent peptide $(10 \mu \mathrm{g} / \mathrm{ml})$. In other adjacent tissue sections from the NAC, the primary antibody for LE was incubated with $50 \mu \mathrm{g} / \mathrm{ml}$ peptide.

For immunoperoxidase labeling, the MOR or LE antibodies were visualized using the avidin-biotin complex (ABC) method (Hsu et al., 1981). Tissue sections were incubated for (1) $30 \mathrm{~min}$ in a 1:400 dilution of biotinylated goat anti-rabbit (for MOR) (Amersham, Arlington Heights, IL) or horse anti-mouse (for LE) (Vector Labs, Burlingame, CA) IgG in
$0.1 \% \mathrm{BSA}$, (2) $30 \mathrm{~min}$ in a 1:100 dilution of peroxidase-avidin complex, and (3) $6 \mathrm{~min}$ in a solution of $22 \mathrm{mg}$ of 3'3-diaminobenzidine (DAB) and $10 \mu \mathrm{l}$ of $30 \% \mathrm{H}_{2} \mathrm{O}_{2}$ in $100 \mathrm{ml}$ of $0.1 \mathrm{M}$ TBS.

For immunogold-silver labeling, the method of Chan et al. (1990) was used to identify the MOR antibody. Tissue sections were (1) incubated for $2 \mathrm{hr}$ in colloidal gold-labeled (1 nm) anti-rabbit IgG (1:50), (2) fixed for $10 \mathrm{~min}$ in $2 \%$ glutaraldehyde in $\mathrm{PBS}$, and (3) reacted for 4-8 min with a silver solution intenSE kit (Amersham). For dual-labeling, the immunoperoxidase reaction for LE was followed by immunogold-silver detection for MOR.

Light and electron microscopy. Sections prepared for light microcopy were rinsed several times in PB, mounted on glass slides, and dried overnight in a desiccator. They were then dehydrated, coverslipped, and examined using a Nikon microscope equipped with differential interference contrast optics.

Sections prepared for electron microscopy were fixed for $60 \mathrm{~min}$ in $2 \%$ osmium tetroxide, dehydrated in a series of graded alcohols and propylene oxide, and flat-embedded in Epon 812 between two pieces of Aclar plastic. Ultrathin sections $(40-50 \mathrm{~nm})$ were cut with a diamond knife (Diatome U.S., Fort Washington, PA) through the NAC at level 12 of Paxinos and Watson (1986) and collected from the outer surface of the plastic-embedded tissue onto copper mesh grids using an LKB ultramicrotome. These sections were then counterstained with lead citrate (Reynolds, 1963) and uranyl acetate and examined with a Philips 201 electron microscope.

Identification of cellular elements. The classification of identified cellular elements was based on descriptions in Peters et al. (1991). Dendrites were identified by the presence of postsynaptic densities and/or the abundance of smooth endoplasmic reticulum. Axons and axon terminals were identified by the presence of small clear synaptic vesicles. Synapses were characterized as either asymmetric (thick postsynaptic densities) or symmetric (thin postsynaptic densities). Nonsynaptic contacts or appositions were defined as close membranous associations that lacked recognizable specializations, but were otherwise not separated by astrocytic processes. Astrocytic processes were defined by their irregular contour and vacuous cytoplasm and the occasional presence of microfilaments.

Ultrastructural analysis. An analysis of the ultrastructural distribution of MOR-LI was carried out to ascertain (1) the prevalence of MOR-LI in association with specific cellular structures and (2) the relationship between MOR and LE-labeled profiles. The prevalence of different profile types (i.e., dendrites vs axons, etc.) containing MOR-LI was expressed as a percentage of all MOR-labeled elements. These MOR-labeled profiles were assessed from three to five vibratome sections from each of seven animals. Animals processed for immunogold-silver detection of MOR $(n=4)$ were used to examine the relative number of gold-silver particles in association with either the plasma membrane or the cytoplasm. Assessment of the immunogold distribution of MOR-LI was based on 710 gold-silver particles within 143 dendrites and 200 gold-silver particles within 68 axons and axon terminals. In dually labeled tissue sections, the cellular relationship between MOR- and LE-labeled profiles was assessed for all contacts/colocalizations between respectively immunoreactive profiles.

\section{RESULTS}

MOR and LE immunoreactivities showed a heterogenous, regional distribution within the NAC (Fig. 1). The light microscopic distribution of MOR-LI was similar to the known distributions of the receptor on the basis of receptor autoradiographic (Mansour et al., 1987; Tempel and Zukin, 1987), in situ hybridization (Mansour et al., 1995a) and immunocytochemistry of antipeptide antibodies raised against similar sequences taken from the same portion of the receptor (Arvidsson et al., 1995; Mansour et al., 1995b). The technique described here produced less intense neuronal perikarya immunoreactivity than that found with the same MOR serum using the conditions of A. Moriwaki and G. Uhl (unpublished observations). The most intensely labeled zones for both the receptor and the peptide were found in the rostral NAC, although more caudal sections still displayed abundant immunoreactivity. Thus, rostral regions were chosen for ultrastructural analysis. Areas containing either MOR (Fig. $1 A$ ) or LE (Fig. $1 B$ ) immunoreactivity were characterized by a punctate labeling pat- 

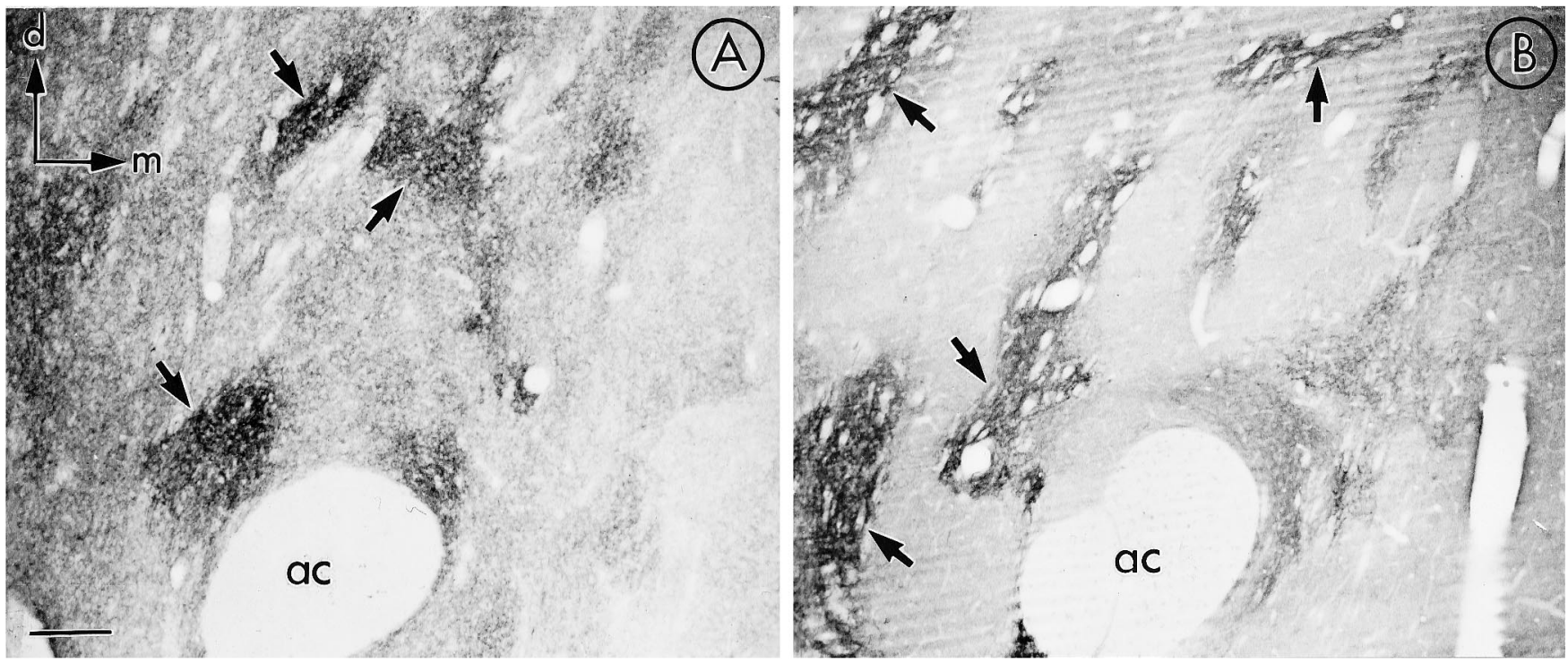

Figure 1. Photomicrographs of MOR $(A)$ and LE $(B)$ show zones (arrows) of the most intense MOR and LE immunoperoxidase labeling in the NAC. Both the receptor and the peptide show a heterogenous distribution of immunoreactivity within this region. $a c$, Anterior commissure; $d$, dorsal; $m$, medial. Scale bar, $50 \mu \mathrm{m}$.

tern. It should be noted that LE represents one of the putative endogenous ligands for MOR, and the NAC is enriched in other opioid peptides.

\section{Antibody specificity}

As immunocytochemical controls, adsorption of the MOR antibody with the corresponding peptide selectively removed both the peroxidase reaction product and the immunogold-silver labeling for MOR and the peroxidase reaction product for LE. At a dilution of 1:15,000 (peroxidase) or 1:10,000 (immunogold-silver) of primary antiserum, MOR-LI produced dense immunolabeling for both methods (Fig. 2A,C). At a dilution of 1:100 of the primary antibody for $\mathrm{LE}$, intense reaction product was detected (Fig. 2E). Preadsorption of the MOR immune serum with 10 $\mu \mathrm{g} / \mathrm{ml}$ of the corresponding MOR peptide greatly reduced the intensity of the peroxidase reaction product (Fig. $2 D$ ) and the number of immunogold-silver particles (Fig. 2B). Similarly, preadsorption of the LE antibody with $50 \mu \mathrm{g} / \mathrm{ml}$ of the parent peptide resulted in a marked reduction of immunolabeling (Fig. 2F).

\section{Localization of MOR-LI in dendrites and its relationship to unlabeled and LE-labeled terminals}

Of 135 MOR-labeled profiles, 64\% were dendrites and/or dendritic spines ( $n=3-5$ tissue sections and $n=7$ animals). In these dendrites, immunoperoxidase as well as immunogold-silver localization of MOR-LI seemed to be associated mainly with plasma membranes (Fig. 3). More diffuse labeling also was seen within the cytoplasm near the immunoreactive plasma membranes when the peroxidase method was used. Assessment of the number of immunogold-silver particles identifying MOR-LI revealed a higher number of immunogold-silver particles in contact with the plasma membrane in dendrites, as compared with the number of particles not in contact with the plasma membrane (Fig. 4); however, immunogold-silver particles identifying MOR-LI were also occasionally contained within the cytoplasm of dendrites and dendritic spines. In many cases, these particles were not associ- ated with identifiable organelles. When detected, labeled organelles were often identified as smooth endoplasmic reticulum.

MOR-LI appeared to be localized preferentially to nonsynaptic sites near unlabeled terminals that often formed either symmetric synapses with dendrites (Fig. $3 A, B$ ) or asymmetric synapses with dendritic spines (Fig. 3C,D). Postsynaptic membrane specializations at asymmetric synapses sometimes seemed to accumulate peroxidase reaction product for MOR (Fig. $3 C$ ) but were not labeled with immunogold detection (Fig. $3 D$ ). Terminals forming either symmetric or asymmetric junctions generally contained loosely packed round or slightly pleomorphic vesicles. More rarely, large dense-core vesicles were seen, usually in terminals forming symmetric synapses. In one favorable section, a dendrite and a spine both labeled for MOR received synaptic contacts from a single unlabeled terminal (Fig. $3 B$ ).

The prominent dendritic localization of MOR-LI was also evident in sections dually labeled for MOR and LE (Fig. 5). In a sample of 100 direct contacts or colocalizations between MORand LE-immunoreactive profiles, 87\% constituted appositions between LE-labeled terminals and MOR-labeled dendrites. Axonal LE-immunoreactive dense-core vesicles were most often localized distal to the appositions with MOR-labeled dendrites (Fig. 5B). LE-labeled terminals apposed to dendrites containing MOR-LI lacked recognizable synaptic specializations or more rarely showed a symmetric (Fig. $5 C$ ) synapse within the sampled sections. The peroxidase labeling for $\mathrm{LE}$ in the terminals either surrounded small clear vesicles (Fig. $5 A, C$ ) or had a more restricted localization in large dense-core vesicles (Fig. $5 B$ ).

MOR-labeled dendrites that contacted LE-reactive terminals were characterized by a comparatively low density of gold-silver particles along portions of their plasma membrane in direct contact with the terminal (Fig. $5 A, B$ ). In contrast, the plasma membranes of spines of these dendrites were intensely immunogoldlabeled (Fig. 5A). The spine heads were recipients of unlabeled terminals forming asymmetric excitatory-type synapses. Goldsilver particles for MOR were also aligned along portions of the 

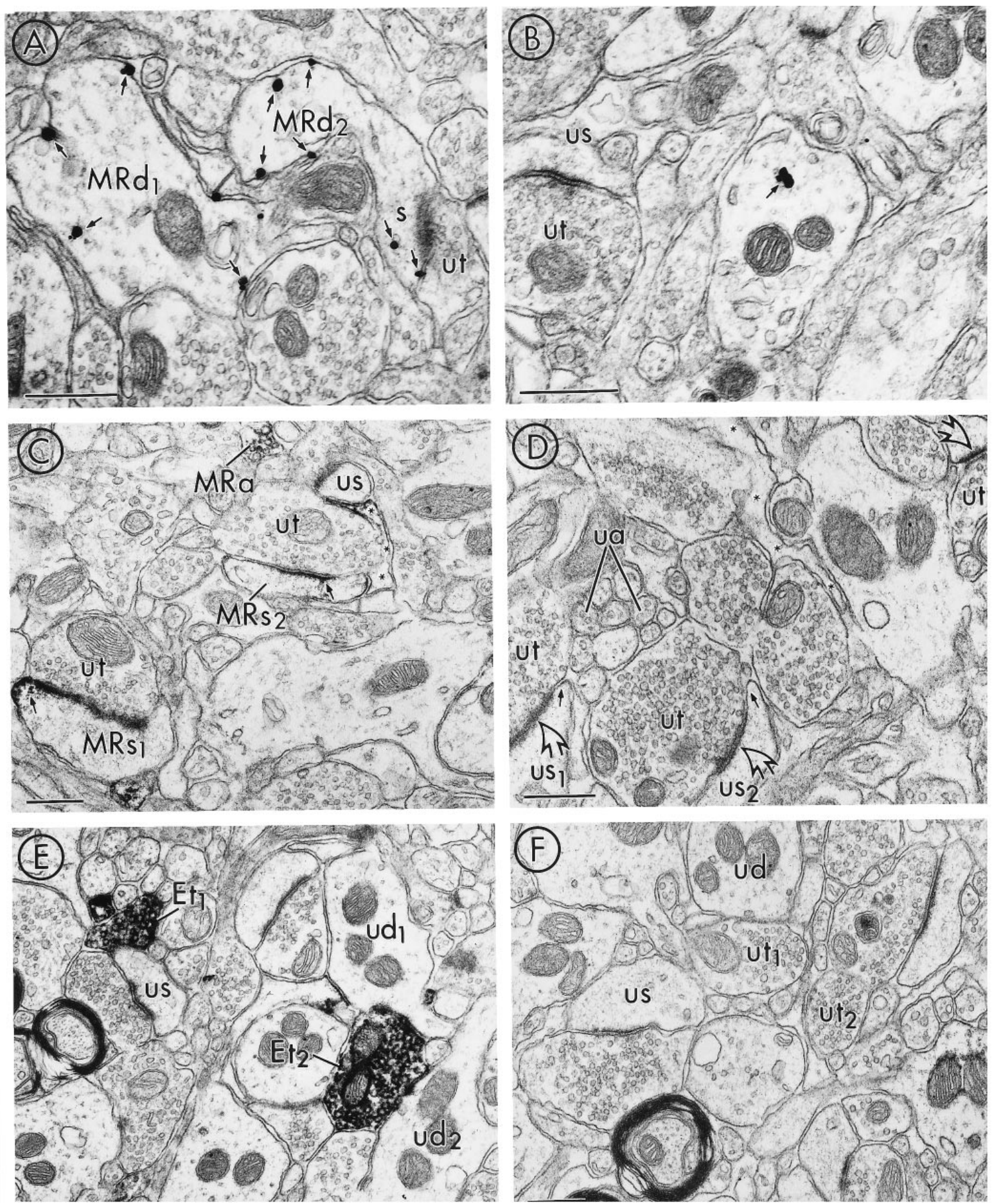

Figure 2. Electron micrographs showing adsorption controls for MOR and LE in adjacent tissue sections from the NAC. $A$ and $C$ show tissue sections processed for immunogold and immunoperoxidase detection of the MOR antibody, respectively. $B$ and $D$ show similarly prepared tissue sections that were immunolabeled using the MOR antibody preadsorbed with the MOR peptide. $E$ shows immunoperoxidase labeling for LE; $F$ illustrates the absence of peroxidase reaction product in adjacent tissue sections, where the LE antibody was incubated with the LE peptide. In $A$, immunogold particles (small arrows) for MOR are associated with the plasma membrane of two dendrites $\left(M R d_{1,2}\right)$ and an emergent spine head $(s)$ in tissue immunolabeled for MOR. $B$ shows one gold particle (small arrow) that was contained within the cytoplasm of a dendrite in tissue preadsorbed with the MOR peptide. In the same field, a dendritic spine that lacks detectable MOR-LI $(u s)$ is apposed to an unlabeled terminal $(u t)$. $C$ shows tissue prepared for MOR immunolabeling, where the peroxidase reaction product for MOR is associated with two dendritic spines $\left(M R s_{1,2}\right)$. The most intense labeling is seen at nonsynaptic regions of the plasma membrane (small arrows). MOR-LI is also seen along specific portions of the membrane of a glial process (asterisks) and in association with vesicles of a small axon $(M R a)$. In $D$, dendritic spines $\left(u s_{1,2}\right)$ lack detectable peroxidase reaction product for MOR in tissue sections preadsorbed with the MOR peptide. Although the nonsynaptic region (small arrows) is devoid of detectable MOR-LI, the synaptic contacts (open arrows) between $u s_{12}$ and two unlabeled terminals (ut) appear similarly electron-lucent to those in $C$. Additionally, a glial process (asterisks) and small axons (ua) are devoid of immunolabeling for MOR. $E$ shows tissue prepared for LE labeling, where the most intense peroxidase reaction product is in association with axon terminals $\left(E t_{1,2}\right) . E t_{1}$ is apposed to an unlabeled spine $(u s)$, whereas $E t_{2}$ is apposed to unlabeled dendrites $\left(u d_{1,2}\right) . F$ illustrates a lack of detectable LE immunoreactivity in tissue that has been preadsorbed with the LE peptide. Scale bars, $0.4 \mu \mathrm{m}$. 

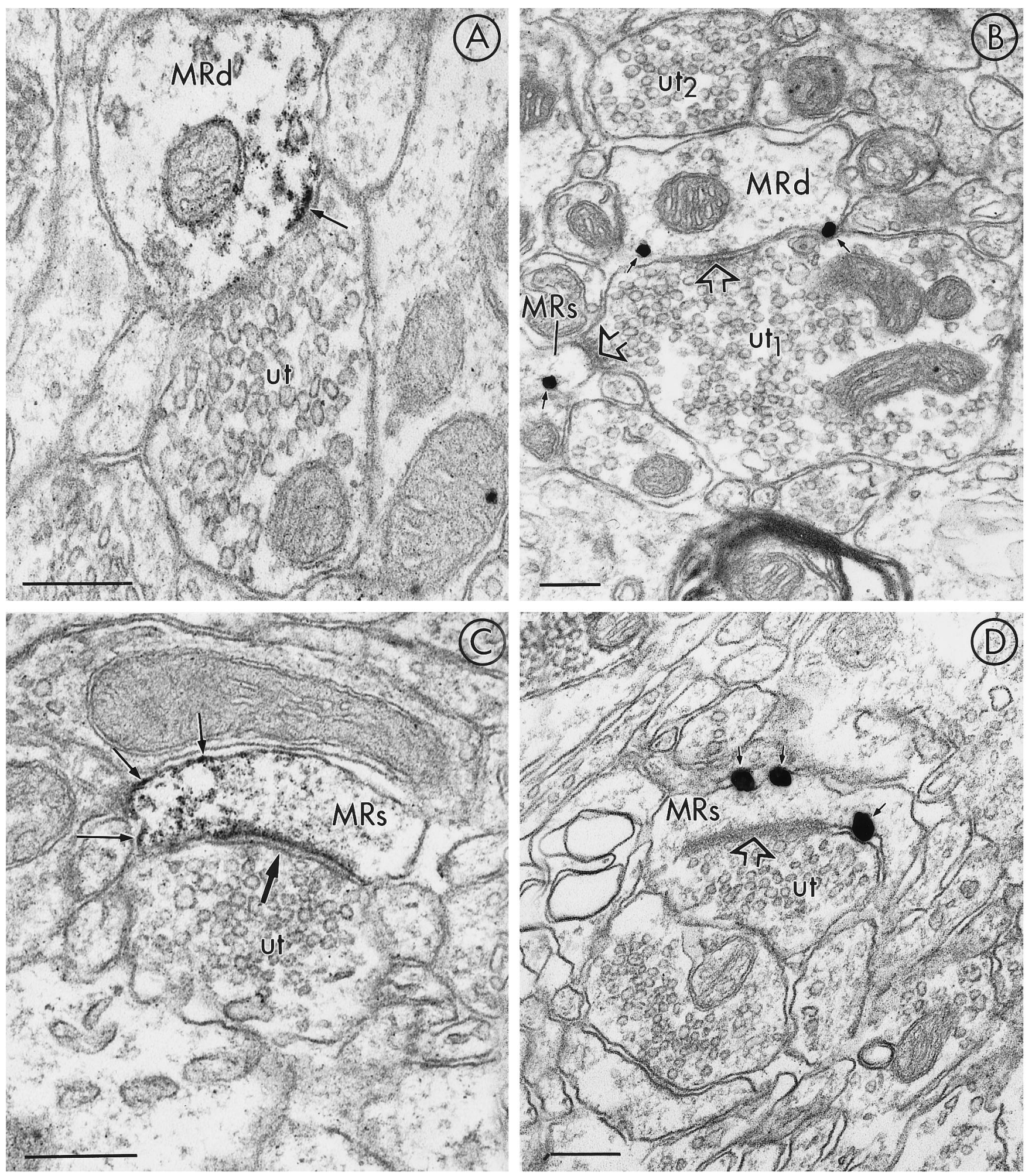

Figure 3. Electron micrographs showing the nonsynaptic localization of MOR-LI in small dendrites and spines. The dendrites $(M R d)$ in $A$ and $B$ are labeled using immunoperoxidase and immunogold-silver, respectively, for detection of MOR-LI. The labeling is largely restricted to nonsynaptic sites in contact with unlabeled terminals ( $u t$ and $u t_{1}$, respectively). The unlabeled terminal $\left(u t_{1}\right)$ in $B$ is also presynaptic to a small spine (MRs) that has one gold particle (arrow), which is near the plasma membrane. The synaptic contacts (open arrows) are both symmetric. No gold-silver particles are seen along portions of the dendrite near $u t_{2}$. In $C$ and $D$, immunoperoxidase and immunogold-silver labeling, respectively, for MOR show mainly extrasynaptic localization of MOR-LI (small arrows) along the plasma membrane of dendritic spines. The spines containing MOR-LI are postsynaptic to unlabeled terminals ( $u t$ in $C$; $u t_{1}$ in $D$ ); however, in $C$ the asymmetric synaptic junction (large arrow) appears immunolabeled only with the peroxidase method. The asymmetric junction (open arrow) in $D$ is not contacted by gold-silver particles. In $D$, a second unlabeled terminal (ut $\left.t_{2}\right)$ is apposed to an unlabeled spine (us). Scale bars, $0.25 \mu \mathrm{m}$. 
Figure 4. Bar graphs showing the subcellular distribution of immunogold-silver particles identifying MOR-LI in dendrites $(n=143)$ and axons or axon terminals $(n=68)$ in the NAC. This graph illustrates the distribution of immunogold-silver particles for MOR in contact with (shaded bar) versus not in contact with (white bar) the plasma membrane. From 710 dendritic gold particles, 513 contacted the plasma membrane, and 197 were contained within the cytoplasm. From 200 axonal gold-silver particles for MOR, 122 contacted the plasma membrane and 78 were associated with the cytoplasm. MOR-LI was identified from three to five vibratome sections that were collected from four animals.

plasma membrane in close proximity to other unlabeled terminals with more clearly defined synaptic junctions (Fig. 5C).

\section{Localization of MOR-LI to axons and axon terminals and their relation to LE}

A smaller although substantial number of unmyelinated axons and axon terminals contained MOR-LI (Fig. 6). Twenty-seven percent of 135 sampled MOR-labeled profiles were axons or axon terminals. In these axons, the most intense peroxidase labeling (Fig. $6 A$ ) and the majority of gold-silver particles for MOR seemed to be associated with the plasma membrane (Fig. 6B,C). Examination of the distribution of immunogold particles revealed a trend toward a greater number of gold particles in contact with the plasma membrane (Fig. 4); however, the differential in the distribution of particles that contacted axonal plasma membranes versus those that did not was not as marked as that seen in dendrites. This trend may be attributed to the relatively smaller sample size of MOR-labeled axons and axon terminals versus dendrites. MOR-LI that was contained within the axonal cytoplasm was associated with saccules of smooth endoplasmic reticulum that were intensely labeled with both peroxidase and immunogold (Fig. 6A,B). Small synaptic vesicles, especially those near the plasma membrane, were also intensely labeled with immunoperoxidase, and other vesicles often were labeled more lightly.

In sections dually labeled for MOR and LE, a small number of axons were found to express both immunoreactivities (Fig. 6C), whereas other MOR-immunoreactive terminals were apposed to LE-labeled axons (Fig. 6D). Of 100 sampled profiles showing associations between MOR and LE, 4\% colocalized the markers in axons and 3\% showed MOR- and LE-labeling in separate apposing axons and/or axon terminals. In axons where the two antigens were colocalized, gold-silver particles identifying MOR generally were localized to the plasma membrane, whereas peroxidase reaction product for $\mathrm{LE}$ was distributed more diffusely throughout the axons. Apposing labeled axons showed a similar immunolabeling pattern. Gold-silver particles for MOR generally were aligned along the axonal plasma membrane, and the peroxidase reaction product for LE was diffusely distributed. The apposed membranes usually were closely spaced but showed no obvious synaptic specializations.

\section{Astrocytic localization of MOR-LI and its relation to LE-labeling}

MOR-LI rarely was localized to non-neuronal sites. Nine percent of profiles containing MOR-LI $(n=135)$ had morphological features of astrocytic processes (Fig. 7), as defined by Peters et al. (1991). Peroxidase (Fig. 7A) and immunogold-silver (Fig. 7B) labeling showed MOR-LI localized to discrete portions of astrocytic processes. Labeled astrocytic plasma membranes often apposed unlabeled terminals in sections processed for single MORlabeling (Fig. 7A). In dually labeled tissue, astrocytic processes labeled for MOR were seen infrequently in close apposition to LE-labeled terminals (Fig. 7B). It also was uncommon to observe immunogold particles for MOR in association with astrocytic organelles such as saccules of smooth endoplasmic reticulum or mitochondria (Fig. 7B).

\section{DISCUSSION}

The results of the present study provide the first ultrastructural evidence that in the rat NAC, MOR is localized most prominently to extrasynaptic sites along plasma membranes of dendrites. These dendrites received input from LE-immunoreactive and nonimmunoreactive terminals. These results indicate that the reinforcing properties of opiates active at MOR in the NAC may be attributed largely to changes in the receptivity of target neurons to opioid peptide and other excitatory and inhibitory inputs. Our results also demonstrate sites, although less numerous, along axonal and glial plasma membranes where opiates may alter the presynaptic release of transmitters or astrocytic function, respectively. Thus, although our results strongly support the role of MOR in modulating the postsynaptic responses to other trans- 




Figure 5. Electron micrographs in $A-C$ show dendrites containing immunogold-labeling for MOR (MRd) that are apposed to terminals containing peroxidase labeling for LE (Et). The dendrite labeled for MOR-LI in $A$ has one gold-silver particle (top, small arrow) opposite Et, whereas the majority of particles (small arrows) are located along the plasmalemma of the head and neck of the spine ( $s$ ) emerging from $M R d$. This spine receives an asymmetric synapse (open arrow) from an unlabeled terminal (ut). Each of the gold particles in the nearby dendrite and spine are also in contact with plasma membranes. $B$ shows immunogold-silver labeling for MOR associated with both the plasma membrane and cytoplasmic organelles (small arrows) within a dendrite $(M R d) . M R d$ is apposed to a terminal showing immunoperoxidase label for LE $(E t)$. In this terminal, the peroxidase is intensely localized to a large vesicle $(l v) . M R d$ also receives a symmetric synapse (open arrow) from an unlabeled terminal ( $u t$ ). In $C$, a longitudinally sectioned dendrite (MRd) shows gold-silver immunolabeling for MOR (small arrows) localized along the plasma membrane, distal to Et. MRd is also postsynaptic to an unlabeled terminal $\left(u t_{1}\right)$ where the synaptic specialization (open arrow) appears asymmetric. The peroxidase-labeled Et can be compared with a second unlabeled terminal $\left(u t_{2}\right)$ in the same field. Scale bars, $0.3 \mu \mathrm{m}$. 

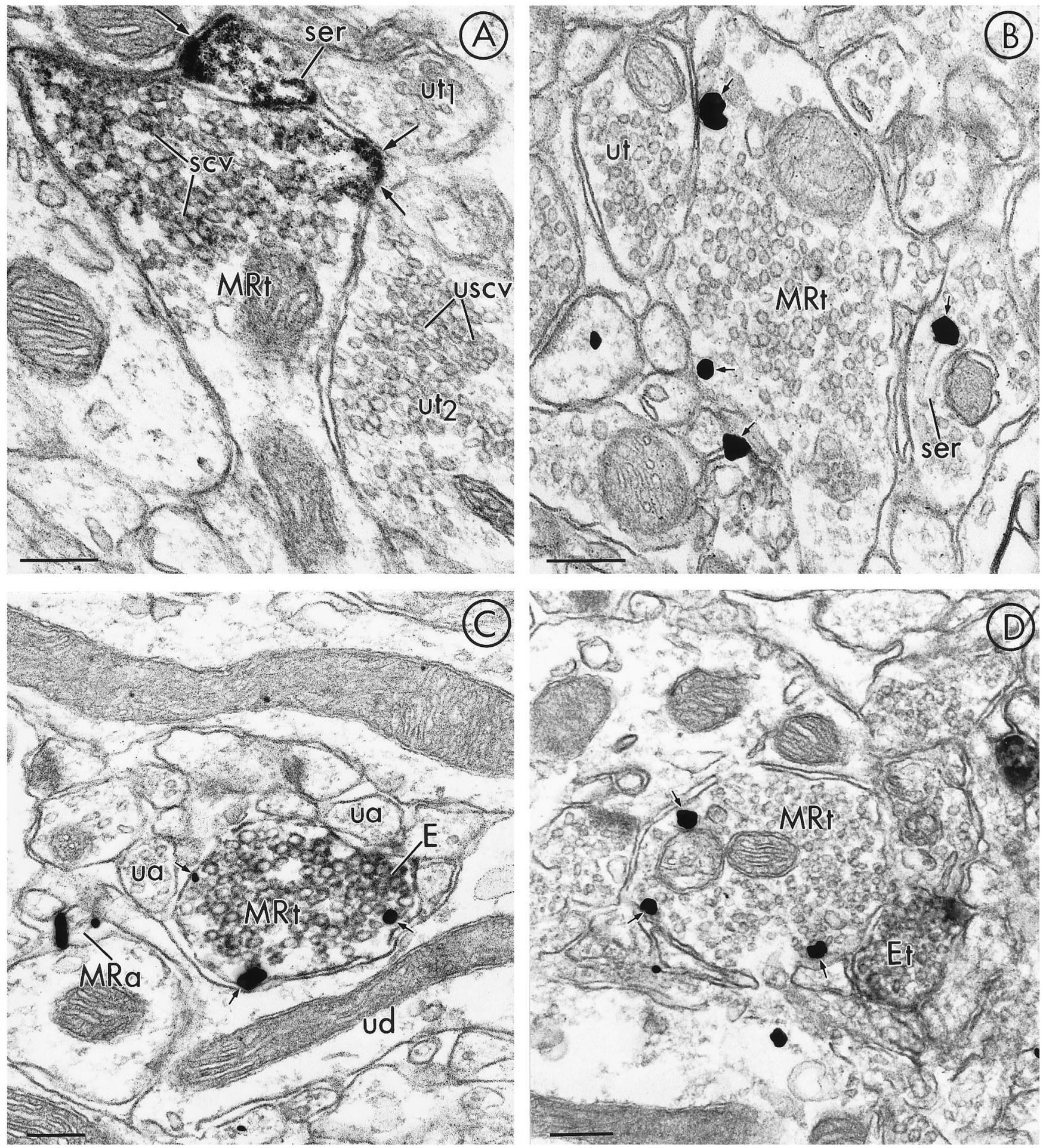

Figure 6. Electron micrographs showing axonal localization of MOR-LI in relation to unlabeled and LE-labeled terminals. In $A$ (immunoperoxidase) and $B$ (immunogold-silver), single-labeling for MOR is seen primarily along the plasma membrane (small arrows) of axon terminals (MRt), apposed to unlabeled axon terminals $\left(u t_{1,2}\right.$ in $A$ or $u t$ in $\left.B\right)$. Membranes of small clear vesicles $(s c v)$ in $M R t$ of $A$ are lightly labeled, whereas in $u t_{2}$, small clear vesicles lack MOR-immunoreactivity (USCV). In contrast, the plasma membrane (small arrow) and a saccule of smooth endoplasmic reticulum (ser) in a nearby axon are both intensely immunoreactive. In $C$ and $D$, respectively, gold-silver labeling for MOR is seen in axon terminals $(M R t)$, which either contain peroxidase reaction product for LE $(E)$ or are apposed to an LE-immunoperoxidase labeled terminal $(E t)$. Both axon terminals show MOR gold-silver particles (small arrows) on or near the plasma membrane. The MRt in $C$ is apposed to several small unlabeled axons $(u a)$ and an unlabeled dendrite $(u d)$. In a nearby small unmyelinated axon $(M R a)$, gold-silver MOR-LI is also seen. Scale bars, $0.2 \mu \mathrm{m}$. 

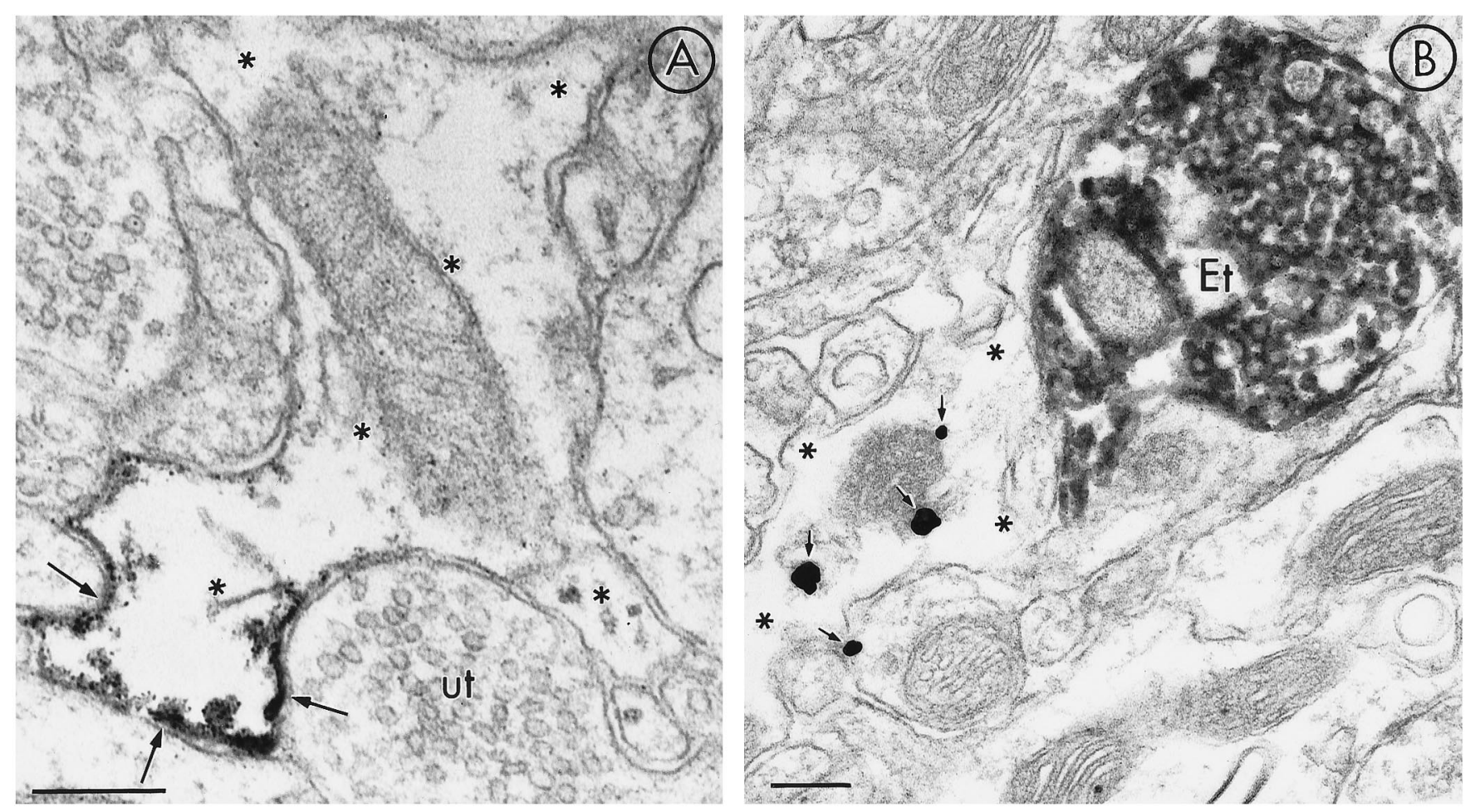

Figure 7. Immunoperoxidase and immunogold-silver localization of MOR-LI in astrocytic processes (asterisks). The electron micrograph in $A$ shows peroxidase product for MOR localized to discrete portions of the astrocytic plasma membrane (arrows) apposed to an unlabeled axon terminal. The immunogold-silver particles in the micrograph of $B$ show MOR-LI (arrows) mainly within the cytoplasm of an astrocytic process that is contacted by an LE-labeled terminal $(E t)$. Scale bars, $0.3 \mu \mathrm{m}$.

mitters in the NAC, they also indicate more diverse functions that are of potential importance for opiate reward.

\section{Methodological considerations}

The term MOR-LI was used to describe the localization of the antibody used in this study to include the possibility that the antiserum may recognize structurally similar proteins. On the basis of several lines of evidence, however, including adsorption controls at the electron microscopic level, we believe that the antibody specifically recognizes MOR (see Materials and Methods) (Surratt et al., 1994). In addition, recent studies by Kaneko et al. (1995), Mansour et al. (1995b), Arvidsson et al. (1995), and A. Moriwaki and G. Uhl (unpublished observations) used antibodies raised against similar sequences taken from the same portion of the receptor. They have shown that the light microscopic distribution of MOR-LI in the rat caudate-putamen, NAC, and spinal cord is similar to what we have observed. Our localization of MOR-LI is also in accordance with preliminary electron microscopic findings in the NAC (Svingos et al., 1995b) and dorsal horn of the spinal cord (Cheng et al., 1995).

Dual-labeling techniques may cause interference between two antigens or underestimate the number of labeled processes. The latter problem is especially true for the immunogold-silver detection method, which can display greater resolution but lower sensitivity than the ABC method. Freeze-thawing tissue to enhance antibody penetration and collecting thin sections at the tissue surface near the Epon-tissue interface was used to minimize these problems. Longitudinally sectioned profiles, however, provide clear evidence that many coronal sections might not exhibit detectable immunolabeling through labeled processes. Because this difficulty should also apply virtually equally to all coronally cut profiles, conclusions regarding prominent extrasynaptic localization of MOR are likely to retain validity.

\section{MOR is localized principally to extrasynaptic dendritic and axonal plasma membranes}

Intense immunolabeling for MOR-LI was localized to discrete extrasynaptic portions of dendritic and axonal plasma membranes in the NAC. This localization suggests similarities with the more dorsal caudate-putamen nuclei, where Hamel and Beaudet (1984, 1987) found that $64 \%$ of the autoradiographic binding sites for MOR ligands seemed to be extrasynaptic. Likewise, with use of the in vitro autoradiographic technique of Hamel and Beaudet, evidence for functional nonsynaptic MOR also has been shown in the guinea pig median eminence, an area devoid of synapses (Beauvillain et al., 1992). Because both the immunogold-silver and immunoperoxidase localizations of MOR-LI in the present study were restricted largely to extrasynaptic sites, we believe that these localizations are representative of the distributions of functional receptors. We cannot exclude entirely, however, effects attributable to lack of antibody penetration at postsynaptic densities as described recently for $\mathrm{GABA}_{\mathrm{A}}$ receptors (Nusser et al., 1995). Because the peroxidase method readily labeled postsynaptic junctions for $\delta$-opioid receptors (DOR) in limbic cortex in similarly prepared sections (Svingos et al., 1995a), the occasionally observed postsynaptic labeling of asymmetric junctions seen in the present study may also indicate that MOR could directly modulate excitatory postsynaptic responses in the NAC. Moreover, the preferential localization of MOR-LI to plasma membranes presents an anatomical correlate for electrophysiological data show- 
ing that activation of MOR alters synaptic membrane potentials (Hori et al., 1992; Capogna et al., 1993). The discrete extrasynaptic localization of MOR-LI provides a cellular basis for understanding opiate reinforcement, because the decreases in synaptic transmission associated with stimulation of MOR in the NAC are thought to underlie drug reward (Yuan et al., 1992).

MOR-LI was associated less frequently with cytoplasmic organelles of both dendrites and axons. Dendritic labeling for MOR was localized to smooth endoplasmic reticulum, whereas axonal MOR was associated with smooth endoplasmic reticulum and/or small clear vesicles. Conceivably, a proportion of peroxidaselabeled vesicles could represent diffusion of labeling reagents. Previous work in similarly prepared tissue, however, has localized DOR to synaptic vesicles (Svingos et al., 1995a). The localization of MOR-LI to smooth endoplasmic reticulum and synaptic vesicles thus is most likely to reflect sites of receptor internalization and/or local reconstitution of the receptor (Broadwell and Cataldo, 1983; for review, see Smith and Warren, 1991). Labeling of these subcellular organelles could also indicate that MOR localization away from the plasma membrane represents the transportation of synthesized receptors to functional sites and/or degradation (Beauvillain et al., 1992).

\section{MOR-labeling is localized to nonsynaptic sites on dendrites contacted by unlabeled and LE-labeled terminals}

Dendrites and dendritic spines labeled for MOR-LI were mainly postsynaptic to unlabeled terminals that formed symmetric or asymmetric synapses, characteristically defined as inhibitory and excitatory input, respectively (Carlin et al., 1980; Hendry et al., 1983). The nonsynaptic location of MOR-LI in these dendrites suggests that MOR in the NAC could modulate either GABAergic or glutamatergic postsynaptic potentials via ion channels, as has been demonstrated electrophysiologically in NAC neurons (Siggins et al., 1995). The mechanism by which MOR-mediated G-protein activation modulates synaptic transmission may be associated with G-protein-linked ion channels, where stimulation of MOR increases potassium conductance (North et al., 1987) and inhibits calcium currents (Schroeder et al., 1991; Stefani et al., 1994). This may result in modulation of neuronal excitability and/or changes in phospholipase $\mathrm{C}$ and adenylate cyclasemediated phosphorylation cascades impacting targets that can include ion channels.

Dendrites immunoreactive for MOR were also apposed to and more rarely received symmetric synapses from axon terminals labeled for LE. In junctions with LE-labeled as well as unlabeled terminals, the gold-silver particles for MOR usually were not located along synaptic junctions. Taken together, these results indicate that MOR in the NAC may be activated at a distance from the sites of exocytotic release of LE or other endogenous opioid peptides, as has been suggested in the peripheral nervous system (Jan and Jan, 1983; Kravitz et al., 1983) and from studies of peptide exocytosis (Thureson-Klein and Klein, 1990). Additionally, our data provide anatomical evidence that postsynaptic activation of MOR in the NAC may occur via stimulation by local endogenous opioids.

\section{MOR is localized to plasma membranes of axon terminals, some of which either colocalize or appose LE-labeled terminals}

Our localization of MOR-LI to axons and axon terminals that lack detectable LE suggests sites for presynaptic modulation of the release of other neurotransmitters within the NAC. These may include acetylcholine or GABA, both of which are modulated presynaptically by MOR agonists in the NAC and dorsal striatum, respectively (Heijna et al., 1992; Jiang and North, 1992). MOR can also regulate dopamine release (Heijna et al., 1990), at least in part through presynaptic mechanisms (Yuan et al., 1992; Pennartz et al., 1994) and $\mathrm{GABA}_{\mathrm{A}}$ receptor potentials (Siggins and Zieglgansberger, 1981), both of which have been implicated in the rewarding effects of opiates (Koob, 1992).

Observed colocalizations of MOR-LI and LE in certain terminals, and in appositions between other terminals labeled separately for these antigens, provide cellular sites for MOR "autoreceptors" and nonautoreceptors. These data support physiological studies showing that stimulation of MOR by morphine can decrease cellular responses (Hakan and Henriksen, 1995) and reduce enkephalin release (Collin et al., 1994). Additionally, our results support previous studies showing axo-axonic appositions between enkephalin- and nonenkephalin-containing terminals (Pickel et al., 1980) and again support a local origin for presynaptic activation of MOR.

\section{Localization of MOR to non-neuronal sites}

The localization of MOR-LI to astrocytic processes in the NAC may provide direct evidence for cellular sites at which endogenous opioids and opiates may modulate non-neuronal physiological responses. These results fit with findings of Beauvillain et al. (1983), Lightman et al. (1983), and Eriksson et al. (1990), who showed evidence for MOR on glial cells of the median eminence, pituitary gland, and primary neuronal cultures, respectively. Although the functional significance of this finding remains to be investigated, it has been proposed that receptors localized to glia (Aoki and Pickel, 1992) may be involved in the regulation of adenylate cyclase, cAMP-dependent phosphorylation, or $\mathrm{IP}_{3}$ turnover and its interaction with calcium and kinases (Browning and Ruina, 1984; Stone et al., 1990). Contact between MOR-labeled astrocytes and LE-labeled terminals suggests a possible substrate for the exchange of signals between astrocytic processes and neurons, where it is thought that astroglial cells may participate in neuronal communication (Eriksson et al., 1991). The localization of MOR-LI to astrocytic processes may also indicate their involvement in drug-associated synaptic plasticity, because alterations in astrocytic protein synthesis and release have been seen in morphine-treated brains (Ronnback and Hansson, 1988).

\section{REFERENCES}

Aoki C, Pickel VM (1992) C-Terminal tail of $\beta$-adrenergic receptors: immunocytochemical localization within astrocytes and their relation to catecholaminergic neurons in $N$. tractus solitarii and area postrema. Brain Res 571:35-49.

Arvidsson U, Reidl M, Chakrabarti S, Lee J-H, Nakano AH, Dado RJ, Loh HH, La P-Y, Wessendorf MW, Elde R (1995) Distribution and targeting of a $\mu$-opioid receptor (MOR1) in brain and spinal cord. J Neurosci 15:3328-3341.

Beauvillain JC, Moyse E, Dutreiz I, Mitchell V, Poulain P, Mazzuca M (1992) Localization of mu opioid receptors on the membranes of nerve endings and tanycytes in the guinea-pig median eminence by electron microscopic radioautography. Neuroscience 49:925-936.

Broadwell RD, Cataldo AM (1983) The neuronal endoplasmic reticulum: its cytochemistry and contribution to the endomembrane system. J Histochem Cytochem 31:1077-1088.

Browning ET, Ruina M (1984) Glial fibrillary acidic protein: norepinephrine stimulated phosphorylation in intact C-6 glioma cells. J Neurochem 42:718-726.

Capogna M, Gahwiler BH, Thompson SM (1993) Mechanism of $\mu$-opioid receptor-mediated presynaptic inhibition in the rat hippocampus in vitro. J Physiol (Lond) 470:539-558. 
Carlin RK, Grab DJ, Cohen RS, Siekovitz P 1980 Isolation and characterization of postsynaptic densities from various brain regions. Cell Biol 86:831-843.

Chan J, Aoki C, Pickel VM (1990) Optimization of differential immunogold-silver and peroxidase labeling with maintenance of ultrastructure in brain sections before plastic embedding. J Neurosci Methods 33:113-127.

Chen Y, Mestek A, Liu J, Hurley JA, Yu L (1993) Molecular cloning and functional expression of a $\mu$ opioid receptor from rat brain. Mol Pharmacol 44:8-12.

Cheng PY, Moriwaki A, Wang JB, Uhl GR, Pickel VM (1995) Ultrastructural localization of $\mu$-opioid receptor immunoreactivity and relationship to enkephalin in cervical dorsal horn of the rat spinal cord. Analgesia 1:363-366.

Chieng B, Christie MJ (1994) Inhibition by opioids acting on $\mu$-receptors of GABAergic and glutamatergic postsynaptic potentials in single rat periaqueductal gray neurones in vitro. Br J Pharmacol 113:303-309.

Collin E, Mauborgne A, Bourgoin A, Benoliel JJ, Hamon M, Ceselin F (1994) Morphine reduces the release of met-enkephalin-like material from the rat spinal cord in vivo by acting at $\delta$ opioid receptors. Neuropeptides 27:75-83.

Delfs JM, Kong H, Mestek A, Chen Y, Yu L, Reisine T, Chesselet M-F (1994) Expression of mu opioid receptor mRNA in rat brain: an in situ hybridization study at the single cell level. J Comp Neurol 345:46-68.

Eriksson PS, Hansson E, Ronnback L (1990) Opiate receptors in neuronal primary cultures. Neuropharmacology 29:799-804.

Eriksson PS, Hansson E, Ronnback L (1991) Mu and delta opiate receptors in neuronal and astroglial primary cultures from various regions of the brain-coupling with adenylate cyclase, localisation on the same neurones and association with dopamine $\left(\mathrm{D}_{1}\right)$ receptor adenylate cyclase. Neuropharmacology 30:1233-1239.

Goeders NE, Lane JD, Smith JE (1984) Self-administration of methionine enkephalin into the nucleus accumbens. Pharmacol Biochem Behav 20:451-455.

Hakan RL, Henriksen SJ (1987) Systemic opiate administration has heterogenous effects on activity recorded from nucleus accumbens neurons in vivo. Neurosci Lett 83:307-312.

Hakan RL, Henriksen SJ (1995) Neuropharmacology of the nucleus accumbens: systemic morphine effects on single-unit responses evoked by ventral pallidum stimulation. Neuroscience 63:85-93.

Hamel E, Beaudet A (1984) Electron microscopic autoradiographic localization of opioid receptors in rat neostriatum. Nature 312:155-157.

Hamel E, Beaudet A (1987) Opioid receptors in rat neostriatum: radioautographic distribution at the electron microscopic level. Brain Res 401:239-257.

Heijna MH, Hogenboom F, Mulder AH, Schoffelmeer ANM (1992) Opioid receptor-mediated inhibition of ${ }^{3} \mathrm{H}$-dopamine and $14 \mathrm{C}$ acetylcholine release from rat nucleus accumbens slices. A study on the possible involvement of $\mathrm{K}+$ channels and adenylate cyclase. Naunyn Schmiedebergs Arch Pharmacol 345:627-632.

Heijna MH, Padt M, Hogenboom F, Portoghese PS, Mulder AH, Schoffelmeer ANM (1990) Opioid receptor-mediated inhibition of dopamine and acetylcholine release from rat brain slices: differences between nucleus accumbens, olfactory tubercle and frontal cortex in receptor types involved. Eur J Pharmacol 181:267-278.

Hendry SHC, Houser CR, Jones EG, Vaughn JE (1983) Synaptic organization of immunocytochemically identified GABA neurons in the monkey sensory-motor cortex. J Neurocytol 12:639-660.

Hori Y, Endo K, Takahashi T (1992) Presynaptic inhibitory action of enkephalin on excitatory transmission in superficial dorsal horn of rat spinal cord. J Physiol (Lond) 450:673-685.

Hsu S-M, Raine L, Fanger H (1981) Use of avidin-biotin-peroxidase complex (ABC) immunoperoxidase techniques: a comparison between $\mathrm{ABC}$ and unlabeled antibody (PAP) procedures. J Histochem Cytochem 29:577-580.

Hughes J, Kosterlitz H, Smith T (1980) The distribution of methionineenkephalin and leucine-enkephalin in the brain and peripheral tissues. In: The pharmacological basis of therapeutics, 6th Ed (Goodman LS, Gilman A, eds), pp 494-543. New York: Macmillan.

Jan YN, Jan LY (1983) A LHRH-like peptidergic neurotransmitter capable of "action at a distance" in autonomic ganglia. Trends Neurosci 6:320-325.

Jiang ZG, North RA (1992) Pre- and postsynaptic inhibition by opioids in rat striatum. J Neurosci 12:356-361.
Kaneko T, Minami M, Satoh M, Mizuno N (1995) Immunocytochemical localization of $\mu$-opioid receptor in the rat caudate-putamen. Neurosci Lett 184:149-152.

Koob GF (1992) Drugs of abuse: anatomy, pharmacology and function of reward pathways. Trends Pharmacol Sci 13:177-184.

Koob GF, Bloom FE (1988) Cellular and molecular mechanisms of drug dependence. Science 242:715-723.

Koob GF, Pettit HO, Ettenberg A, Bloom FE (1984) Effects of opiate antagonists and their quaternary derivatives on heroin selfadministration in the rat. J Pharmacol Exp Ther 229:481-486.

Kravitz EA, Beltz BS, Glusman S, Goy MF, Harris-Warick RM, Livingstone MS, Schwartz TL, Siwicki KK 1983 Neurohormones and lobsters: biochemistry to behavior. Trends Neurosci 6:345-349.

Leranth C, Pickel VM (1989) Electron microscopic pre-embedding double immunostaining methods. In: Tract tracing methods 2, recent progress (Heimer L, Zaborsky L, eds), pp 129-172. New York: Plenum.

Lightman SL, Ninkovic M, Hunt SP, Iverson LI (1983) Evidence for opiate receptors on pituicytes. Nature 305:235-236.

Mansour A, Fox CA, Akil H, Watson SJ (1995a) Opioid-receptor mRNA expression in the rat CNS: anatomical and functional implications. Trends Neurosci 18:22-29.

Mansour A, Fox CF, Burke S, Akil H, Watson SJ (1995b) Immunohistochemical localization of the cloned $\mu$ opioid receptor in the rat CNS. J Chem Neuroanat 8:283-305.

Mansour A, Khachaturian H, Lewis ME, Akil H, Watson SJ (1987) Autoradiographic differentiation of $\mu, \delta$, and $\kappa$ opioid receptors in the rat forebrain and midbrain. J Neurosci 7:2445-2464.

McCarthy PS, Walker RJ, Woodruff GN (1977) Depressant action of enkephalins on neurons in the nucleus accumbens. J Physiol (Lond) 267:40.

McLean S, Rothman RB, Herkenham M (1986) Autoradiographic localization of $\mu$ - and $\delta$-opiate receptors in the forebrain of the rat. Brain Res 378:49-60.

Meredith GE, Ingham CA, Voorn P, Arbuthnott GW (1993) Ultrastructural characteristics of enkephalin-immunoreactive boutons and their postsynaptic targets in the shell and core of the nucleus accumbens of the rat. J Comp Neurol 332:224-236.

Milner TA, Pickel VM, Reis DJ (1989) Ultrastructural basis for interaction between central opioids and catecholamines. I. Rostral ventrolateral medulla. J Neurosci 9:2114-2130.

Negus SS, Dykstra LA (1989) Neural substrates mediating the reinforcing properties of opioid analgesics. In: Focus on biochemistry and physiology of substance abuse, Vol 1 (Foster RR, ed), pp 211-242. Boca Raton, FL: CRC.

Negus SS, Hendrikson SJ, Mattox A, Pasternak GW, Portoghese PS, Takemori AE, Weigner MB, Koob GF (1993) Effects of antagonists selective for $m u$, delta and kappa opioid receptors in the reinforcing effects of heroin in rats. J Pharmacol Exp Ther 265:1245-1252.

North RA, Williams JT, Suprenant A, Christie MJ (1987) $\mu$ and $\delta$ opioid receptors both belong to a family of receptors that are couples to potassium channels. Proc Natl Acad Sci USA 84:5487-5491.

Nusser Z, Roberts JD, Baude A, Richards JG, Somogyi P (1995) Relative densities of synaptic and extrasynaptic $\mathrm{GABA}_{\mathrm{A}}$ receptors on cerebellar granule cells as determined by a quantitative immunogold method. J Neurosci 15:2948-2960.

Paxinos G, Watson C (1986) The rat brain in stereotaxic coordinates. New York: Academic.

Pennartz CM, Groenewegen HJ, Lopes da Silva FH (1994) The nucleus accumbens as a complex of functionally distinct neuronal ensembles: an integration of behavioral, electrophysiological and anatomical data. Prog Neurobiol 42:719-761.

Peters A, Palay SL, Webster H deF (1991) The fine structure of the nervous system, neurons and their supporting cells, 3rd ed. New York: Oxford UP.

Pickel VM, Sumal KK, Beckley SC, Miller RJ, Reis DJ (1980) Immunocytochemical localization of enkephalin in the neostriatum of rat brain: a light and electron microscopic study. J Comp Neurol 189:721-740.

Reynolds ES (1963) The use of lead citrate at high $\mathrm{pH}$ as an electronopaque stain in electron microscopy. J Cell Biol 17:208.

Ronnback L, Hansson E (1988) Are astroglial cells involved in morphine tolerance? Neurochem Res 13:87-103.

Rossi GC, Pan XY, Brown GP, Pasternak GW (1995) Antisense mapping of the MOR-1 opioid receptor: evidence for alternative splicing and a novel morphine-6 beta-glucuronide receptor. FEBS Lett 369:192-196. 
Schroeder JE, Fischbach PS, Zheng D, McCleskey EW (1991) Activation of $\mu$ opioid receptors inhibits transient high- and low-threshold $\mathrm{Ca}^{2+}$ currents but spares a sustained current. Neuron 6:13-20.

Siggins GR, Zieglgansberger W (1981) Morphine and opioid peptides reduce inhibitory synaptic potentials in hippocampal pyramidal cells in vitro without alteration of membrane potential. Proc Natl Acad Sci USA 78:5235-5239.

Siggins GR, Martin G, Yuan X, Nie Z, Madamba S (1995) Opiate modulation of glutamatergic transmission in nucleus accumbens neurons in vitro. Analgesia 1:728-733.

Simantov R, Childers S, Snyder S (1977) Opioid peptides: differentiation by radioreceptor assay. Brain Res 135:358-367.

Smith E, Warren G (1991) The mechanism of receptor-mediated endocytosis. Eur J Biochem 202:689-699.

Stefani A, Surmeier DJ, Bernardi G (1994) Opioids decrease highvoltage activated calcium currents in acutely dissociated neostriatal neurons. Brain Res 642:339-343.

Stone EA, Sessler FM, Weimin L (1990) Glial localization of adenylate cyclase coupled beta-adrenoreceptors in rat forebrain slices. Brain Res 530:295-300.

Surratt CK, Johnson PS, Moriwaki A, Seidleck BK, Blaschak CJ, Wang JB, Uhl GR (1994) $\mu$-Opiate receptor, charged transmembrane domain amino acids are critical for agonist recognition and intrinsic activity. J Biol Chem 269:20548-20553.
Svingos AL, Cheng PY, Clarke CL, Pickel VM (1995a) Ultrastructural localization of delta opioid receptor and $\mathrm{Met}^{5}$-enkephalin immunoreactivity in rat insular cortex. Brain Res 700:25-39.

Svingos AL, Moriwaki A, Wang JB, Uhl GR, Pickel VM (1995b) Extrasynaptic sites for enkephalin modulation through $\mu$-opioid receptors in rat nucleus accumbens. Analgesia 1:774-777.

Tempel A, Zukin S (1987) Neuroanatomical patterns of the $\mu, \delta$, and $\kappa$ opioid receptors of rat brain as determined by quantitative in vitro autoradiography. Proc Natl Acad Sci USA 84:4208-4312.

Thureson-Klein AK, Klein RL (1990) Exocytosis from neuronal large dense-cored vesicles. Int Rev Cytol 121:67-126.

Vaccarino FJ, Bloom FE, Koob GF (1985) Blockade of nucleus accumbens opiate receptors attenuates the intravenous heroin reward in the rat. Psychopharmacology 86:37-42.

West TEG, Wise RA (1988) Effects of naltrexone on nucleus accumbens, lateral hypothalamic and ventral tegmental self-stimulation ratefrequency functions. Brain Res 462:126-133.

Wise RA (1989) Opioid reward: sites and substrates. Neurosci Biobehav Rev 13:129-133.

Yuan X, Madamba S, Siggins GR (1992) Opioid peptides reduce synaptic transmission in the nucleus accumbens. Neurosci Lett 134:223-228.

Zastawny RL, George SR, Nguyen T, Cheng R, Tsatsos J, Briones-Urbina $\mathrm{R}$, O'Dowd BF (1994) Cloning, characterization and distribution of a $\mu$-opioid receptor in rat brain. J Neurochem 62:2099-2105. 